\title{
Importance of Competences in Communication, as Perceived by Business Leaders
}

\author{
Peter Karácsony ${ }^{1 *}$, Tamás Bokor ${ }^{2}$ \\ ${ }^{1}$ Department of Economics, Faculty of Economics and Informatics, J. Selye University, Elektrárenská cesta 2, SK-94501 Komárno, \\ Slovakia \\ 2 Department of Communication and Media, Institute of Communication and Sociology, Corvinus University of Budapest, Fővám \\ tér 8, H-1093 Budapest, Hungary \\ * Corresponding author, e-mail: karacsonyp@ujs.sk
}

Received: 21 February 2020, Accepted: 18 August 2020, Published online: 21 June 2021

\begin{abstract}
From the perspective of a hierarchically ordered company, the expectations of company leaders concerning their employees' necessary competencies play a greater role than vice versa. This paper light on the expectations of leaders and sub-leaders of micro-, small and medium-sized enterprises concerning the competencies of employees in neighbouring parts of Hungary and Slovakia.

The authors' collected 28 scientific papers on the issue of communication competencies in order to map out 21 "common denominators" derived from the combined competence lists. A survey was conducted with 222 respondents to measure the subjective importance assigned to these traits and to observe the respondents' attitudes towards the effectiveness of communication training programmes they had participated in. On the Hungarian side, speech competence proved to be the most crucial competence for business leaders, followed by attention/reflection and interpersonal communication skills. In Slovakia, persuasion was reported to be the most crucial trait, the second most important is the application of confirmation and feedback, and the third is speech competence.

In terms of the participants' past communication training experiences, the competences of group communication, assertiveness and leadership skills were reported to have been the main areas of focus. The findings indicate that overall satisfaction with communication training programmes depends on neither the amount of participants' leadership experience nor the companies' field(s) of activity, nor the nationality (i.e. the venue) of the companies. The overall satisfaction rate is 2.53 on a four-grade scale among those who ever attended communication training programmes.
\end{abstract}

Keywords

communication, Hungary, management competence, skills, Slovakia

\section{Introduction}

Competences, as individual traits which determine a person's behaviour and abilities and allow them to gain resources for a successful life, have become central to both pedagogy and psychology, as well as human resources practice. Competences are not only important in our everyday lives but play a crucial role in the workplace. In a company's hierarchy, leaders and subordinates, each possessing their individual competencies, influence each other's workplace behaviour and functioning. Beside this influence, they also build up a mental picture out of each other's competencies, thereby creating expectations both concerning what types of knowledge, skills and abilities others in the company should have in order to be able to fulfil their duties and concerning how they should do their job in general.
From the perspective of a hierarchically ordered company, the expectations of company leaders concerning their employees' necessary competencies play a greater role than the opinions of the employees about their leaders' abilities and competencies. Alongside these concerns, we aim with this paper to shed light on the expectations of leaders and sub-leaders of micro-, small and medium-sized enterprises (with varying scopes of activities) in certain neighbouring parts of Hungary and Slovakia concerning the competencies of employees. The results of such research will make it possible to ascertain potential differences between leaders' thinking in the two observed countries. As a further affordance of the research, one can observe how practising leaders in small companies think 
about their subordinates' ideal competence set, enabling the formation of recommendations for a more effective secondary education and vocational training system.

Person and organisation are closely related to each other. Leadership not only forms this relationship but is also a part of it (Gil et al., 2018). The most palpable result of the interaction and communication between managers and subordinates is the efficient functioning of the organisation. Managers work on the basis of principles, methods, abilities, and techniques that enable the organisation to function successfully and maintain long-term competitiveness (Chiniara and Bentein, 2018). This basis includes practices and organisational habits as well.

Managers lead and evaluate employees in different ways. Some are rigorously guiding, aiming towards full control over the subordinates, while others have a much more liberal leadership style to allow employees to develop within the organisation. Depending on the corporate circumstances, managers may, if necessary, use more kinds of leadership styles to create organisational efficiency. The analysis of the impact of leadership style on the organisation has long been at the centre of economic and management research (Akhmedjanov, 2020). Leadership has countless components, and a leader's work can be evaluated from a number of viewpoints. However, perhaps the most important aspect is how a leader treats his/her subordinates, and two of the most important elements of this are the communication of the leader and their expectations towards their employees' abilities and skills.

Leadership, in this approach, focuses primarily on human resources, encouraging people to be engaged through mutual communication (Meiners, 2019). It can be stated that leadership is a process that directs people in such a way that their actions contribute to the realisation of specific organisational goals. Beside this, leadership can be defined as a skill that drives people into action even when they can think of a different way (Cohrs et al., 2019). Karácsony and Machová (2014) say that leadership is effective if the subordinates are sufficiently motivated and have enough experience to carry out the tasks entrusted to them. In this case, the manager can provide more detailed information to his employees, who can better understand their importance, their role and the role of their specific skills in the organisation (Chan and Du-Babcock, 2018).

To become an effective leader, one needs to acquire critical leadership skills, such as:

- qualification: professional knowledge and skills required for the work;
- cognitive skills: the ability to recognise the problem, clear thinking, understanding relationships;

- implementation skills: proper distribution of work, motivation, and communication;

- networking skills: developing effective and cooperative working relationships, critical behaviour and social sense.

Furthermore, there are some specific skills that are crucial to become a successful entrepreneur. According to Yildırım et al. (2019), these are the ability to work together, communication, creativity and emotional intelligence.

At this point, it is necessary to clarify the concepts of skills and competencies, and to enlighten the relations and differences between them. This paper does not attempt to shoulder the task of fully summarising the amazing amount of pedagogical and psychological approaches covered by these two concepts; only a brief overview of them is given, concentrating on human resource concerns.

Competence, in this approach, means the combination of knowledge, skills, abilities, behaviours and their personal application, which helps the employees to successfully perform critical tasks, special functions, and the general duties of the position.

According to Machida-Kosuga (2017), competence expresses ability, skill, knowledge and performance simultaneously. Competence enables the individual to constructively and successfully use the acquired knowledge and personality components (Athey and Orth, 1999). Competence is an ability by which an individual can meet expectations and successfully solve tasks.

Spencer and Spencer's (1993) job competency vocabulary classifies the various characteristics into six groups: performance, action, support, assistance, influence on others, need for power; management activities, cognitive functions, personal efficiency.

Clearly, competence represents a pool of skills which includes - among others - general and specific skills. Furthermore, the concept of competence can be divided into two types. On the one hand, general competencies, features that are essential for good performance, regardless of organisation and type of work, and, on the other hand, specific competencies, which are required only within the given organisation to carry out a particular job (Williams, 2019). The competency model is the framework that links the organisation, the individual, and the job together, serving as a basis for matching the job-related competency expectations and the individual competence set (Hollenbeck et al., 2006). 
Changing market conditions, speeding information traffic and communication technologies also necessitate a change in school teaching methods, and the need to develop key competencies in the context of the requirement for organisations (Warin et al., 2011).

In Goleman's approach (1998), there are two basic groups of competence elements, namely personal competence and social competence. Personal competencies determine how we can deal with ourselves, while social competencies help us manage our social relationships. The study of competences in the job market has become an increasingly widespread method not only for selecting subordinates but also for defining managerial positions, as it provides an overview of management expectations in addition to a general description (Briscoe and Hall, 1999).

Competency-based Human Resource Management Applications came into common practice from 1990 (Lišková and Tomšík, 2013). The competency model application first appeared at the time of selection (Lapierre and McKay, 2002), with the aim of ensuring that the competencies required by the job and the competencies of the person performing the job were met. Later on, the importance of competency appears in other human resource management functions, for example, in training and human resource development (personalised development to ensure that the individual has all the competencies needed to get the job (Vinichenko et al., 2018), in performance management (the worker receives feedback on the level of competence), and in payment (competence-based payment).

Employers determine the competencies and skills expected from prospective employees in advance. According to the American Management Association (American Management Association, 2010), the most common skills expected from new employees are communication skills, collaboration skills/susceptibility of teamwork, critical thinking/problem-solving ability, and creativity/innovation.

In the AMA survey (American Management Association, 2010), more than 2,000 US leaders took part in a survey, the final finding of which was that managers expected their prospective employees to be able to read and write; but they also need the following skills: critical thinking (problem-solving), communication, willingness to cooperate, and creativity (innovation).

According to Ryan (2008), the competencies required for successful management include: leadership, attentive listening, communication, problem-solving, time management, adaptation to change, networking, presentation skills, stress management.
Of the above key competencies, management communication is one of the most important elements of the generally accepted model of the manager role of Mintzberg (1994). In Mintzberg's model, managerial roles form three consecutive levels:

1. level of information,

2. level of people and

3. level of activity, both within the organisational unit and outside the organisational unit.

Communication is the only competence within an organisational unit as well as outside of an organizational unit.

Communication can be found everywhere: we communicate constantly, and it plays a decisive role in the life and development of humanity. Communication itself, as a word, comes from the Latin word "communicare", which means to make something common, with the radix "mun(us)", in English: duty, task, service. Communication can be defined either as information transfer and exchange or as participation in the creation of mutual knowledge in order to solve problems. (Information, in this regard, is any data, fact, or news that is relevant to us, and that expands our knowledge or reduces our ignorance. A problem, furthermore, can be defined as any condition which exceeds the stimulation threshold of the person, causing discomfort for them).

Communication of the organisation is the multidirectional exchange of information (external and internal) in business processes through a specific signal system (Ichimiya, 2019). Effective communication is essential for an organisation to achieve its goals.

In organisational communication, we define external and internal communication areas (Gallo, 2018). External communication is also covered by the company's external relations (Hackman and Johnson, 2004). Here it is important to mention that an organisation's external communication has a major impact on the organisation's relationship with other actors in the economy. The internal communication of the organisation is the basic tool of leadership, which plays a role in all management styles, as it exercises leadership functions through the communication process and strengthens its relationships within the organisation (Smith and Mounter, 2005).

In the next section, we detail the results of a comparative study involving the leaders of Hungarian and Slovakian micro-, small and medium-sized enterprises, observing how they think about the importance of the 
different competencies of their employees'. The scope of this study is narrowed down to those competences that relate to communication in a broad sense.

\section{Methodology}

Competencies of communication - due to their complexity in terms of verbal and nonverbal channels, as well as in terms of its psychological and applied aspects - can be defined only in broad outline. If researchers try to seek for a stable framework of competence analysis, they will find a perplexing amount of resources. Most of the literature items apply different approaches and models to give a structure to the competence system of communication. Thus, the first crucial problem in conducting a survey about the judgement of the importance of different competencies in communication is to give a reasonable definition and limitation to the observed factors.

Corvinus University of Budapest (CUB) launched a research project named "Institutional Developments for Smart Specialisation at the Székesfehérvár Campus of Corvinus University of Budapest" in 2016, in order to serve several research aims and at the same time, broaden their perspective in business network research. In this umbrella project, 13 research groups were founded with different areas of focus in management and network research. Five members of the research group named "KommKomp" (formally called "Efficiency in Business Communication") shouldered the task of measuring business leaders' attitudes towards the importance of different competencies in mediated and non-mediated workplace communication, taking into consideration that more than half of the GDP in Hungary is produced by the SME sector.

The group collected 28 scientific papers on the issue of communication competencies. By comparing them in a meta-analysis, the aim was to find the "common denominators" among the competence lists by picking those competences mentioned in at least two different resources. From the analysed papers, each featuring different approaches and components, 21 well-definable competence elements could be highlighted as follows: appearance, assertive communication and confrontation, attention and reflection, competence in foreign languages, confirmation and feedback, emotional control, explanatory skills, group communication competence, intercultural competence, interpersonal communication, negotiation, non-verbal behaviour, persuasion, presentation skills, proactivity, self-disclosure, self-management, sense of humour, speech competence, usage of ICT and written communication skills.
The aim of the research was to observe and measure the company leaders' opinions and attitudes towards the importance of different communication competencies, to measure their previous experiences and, in case of their having had the latter, their satisfaction with communication training programmes. The target group was firmly defined: specifically, the business leaders of Small and Medium Enterprises (SMEs) of up to 250 employees. As for the geographical limitations, the project had regional limits due to the project description framework. That is why only one region with three counties (the Central Transdanubian region, with Fejér, Komárom-Esztergom and Veszprém counties) was eligible on the Hungarian side. In order to choose a suitable Slovakian region to compare this with, the involved partner institution (J. Selye University, Komárno) chose the neighbouring area, the District of Komárno for involving SMEs from the left bank of the Danube, on the Slovakian side.

The 21 factors listed above provided the basis of the questionnaire, which was supplemented by questions concerning the duration of the respondents' leadership experience, as well as the category, size and scope of their enterprises. In addition, sociodemographic variables like gender and age were recorded. After finalising the questionnaire, a Google Form was created in order to generate a short hyperlink to the survey with 30 questions.

On the Hungarian side, two data resources were used to reach out to business leaders. On the one hand, the own regional contact list of CUB with about 250 contact numbers and e-mail addresses was firstly refreshed by cold calls, and then applied as a means of up-to-date contacts. On the other hand, the National Association of Young Entrepreneurs (FIVOSZ) and the Hungarian Foundation for Enterprise Promotion (MVA) helped the research group to spread the questionnaire link among a regionally filtered target group of entrepreneurs via eDM (electronic direct marketing message). After an A/B testing, the more applicable variation of eDM was sent out to the segmented mailing list. The data recording period ran in July 2018.

On the Komárno side, experts of J. Selye University translated the Hungarian questionnaire into Slovakian (taking the necessary content and language changes into account), then hard copy questionnaires were brought out directly to the enterprises of the university's connection network by students. The data recording period ran in September 2018.

\section{Sampling}

The sample was focused on enterprises with a maximum employee number of 250, which is a limit of the "small and medium enterprises" category in Hungarian economic 
law. Due to the spreading method (eDM and personal network), some major enterprises also appear in the sample: $15-17 \%$ of the respondents work for or in these kinds of firms. In Hungary, 82 respondents work in an enterprise with less than 50 employees (from a total of 116 respondents); the Slovakian sample meanwhile contains 60 enterprises with less than 50 employees among the 106 micro and small enterprises. Only a minor part of the sample (34 of 116 in Hungary, 46 of 106 in Slovakia) counts as medium-sized or major enterprises.

As for the main assignment of the respondents' firms, $19 \%$ are indefinite (given that this was not a required field in the questionnaire), the four main function areas are the financial and insurance sector (14.41\%), manufacturing $(11.71 \%)$, other services $(9.01 \%)$, and trade (9.01\%), according to the Hungarian unified classification sectors of company activities.

The questionnaire measured the age category of the respondents (Fig. 1), and the amount of their leadership experience (in years) (Fig. 2). From these answers, researchers learnt that a good two-thirds of the respondents are between 25-44 years old, while, regarding their work experience, the Slovakian part of the sample tilts towards the lowest possible leadership experience: almost half of the respondents have spent less than two years in leading positions (in the Hungarian sample, this is nearly one-third of the respondents).

\section{Results and discussion}

As the core of the questionnaire, the workplace relevance of 21 different types of communication competencies had to be assessed by company leaders, each on a five-degree scale, where 1 meant the least important while 5 expressed the highest importance. Given that this method handles the assessment of competencies as separated opinions, the results (i.e. the scaling) for each competence are independent from each other. Overall ranking, in other words, is expressed as a list based on the relative importance of these 21 traits, something that could lead to a more structured judgement assessment. However, a caveat is in order: this solution could have blurred the similarities of the importance of some competences due to the need to produce rankings without any ties.

While observing the assessment of the above-mentioned 21 traits, several minor but significant differences were outlined between the Hungarian and Slovakian attitudes. Starting with the univariate analysis of the results, the overall Slovakian assessment of the importance of various communication competencies seems to be lower than the Hungarian one. While the former respondents (SK) attributed an average of 3.71 , with a dispersion of 0.14 , to the listed traits overall, the latter group's (HU) overall average was 4.19 , with a dispersion of 0.24 . The variances are also significantly different, 0.02 in Slovakia and 0.06 in Hungary. The correlation of the two importance lists is $r=0.33$, showing a quite weak but evincible correlation between the two nations' attitudes $(0.3<r<0.7)$. This means that the preference list of these two groups moves more or less together, while the general judgement of the importance of the listed traits is a bit stricter among Slovakian respondents than among Hungarian ones (Fig. 3).

On the Hungarian side, speech competence, with its 4.62 average points, has proved to be the most crucial competence for business leaders, followed by attention and reflection (4.55) and interpersonal communication skills (4.50). In Slovakia, persuasion was reported to be the most crucial trait (average: 4.02), while the second is the application of confirmation and feedback (3.90) and the third is speech competence (3.83).

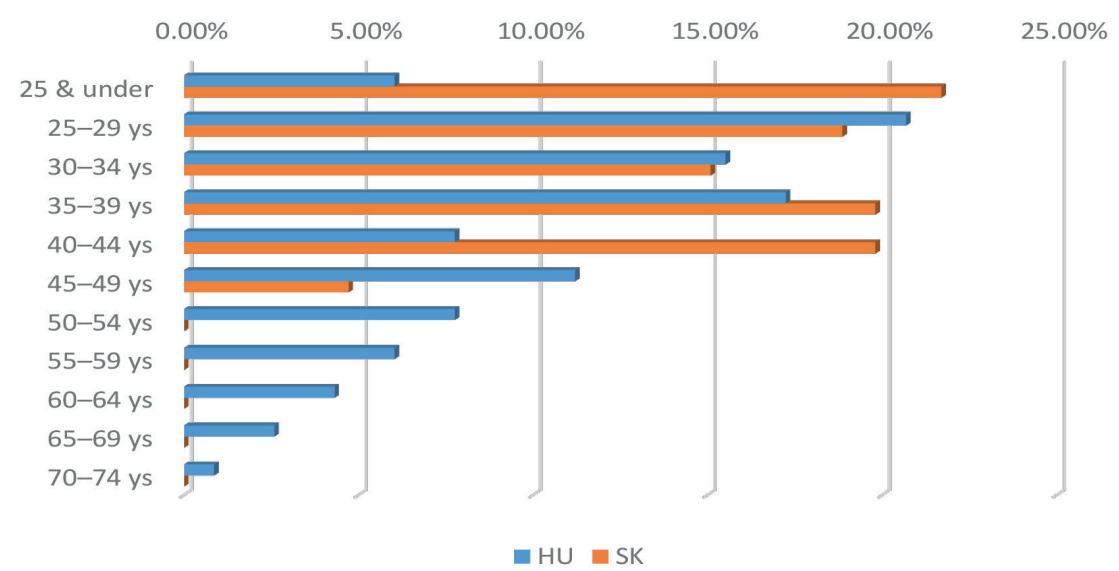

Fig. 1 Age categories of the leaders. Source: Own processing 


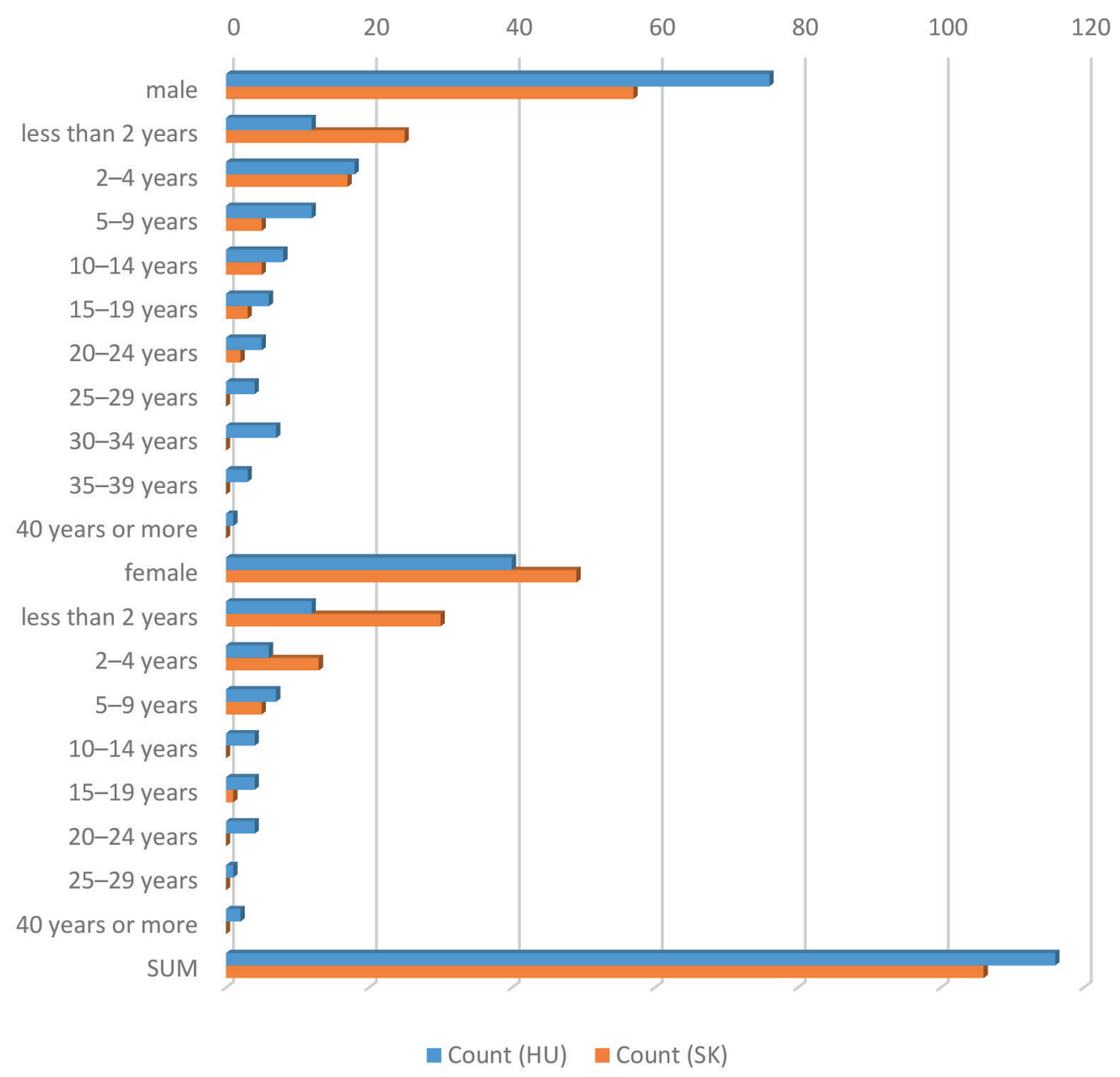

Fig. 2 Leadership experience of the respondents by gender, percentage Source: Own processing

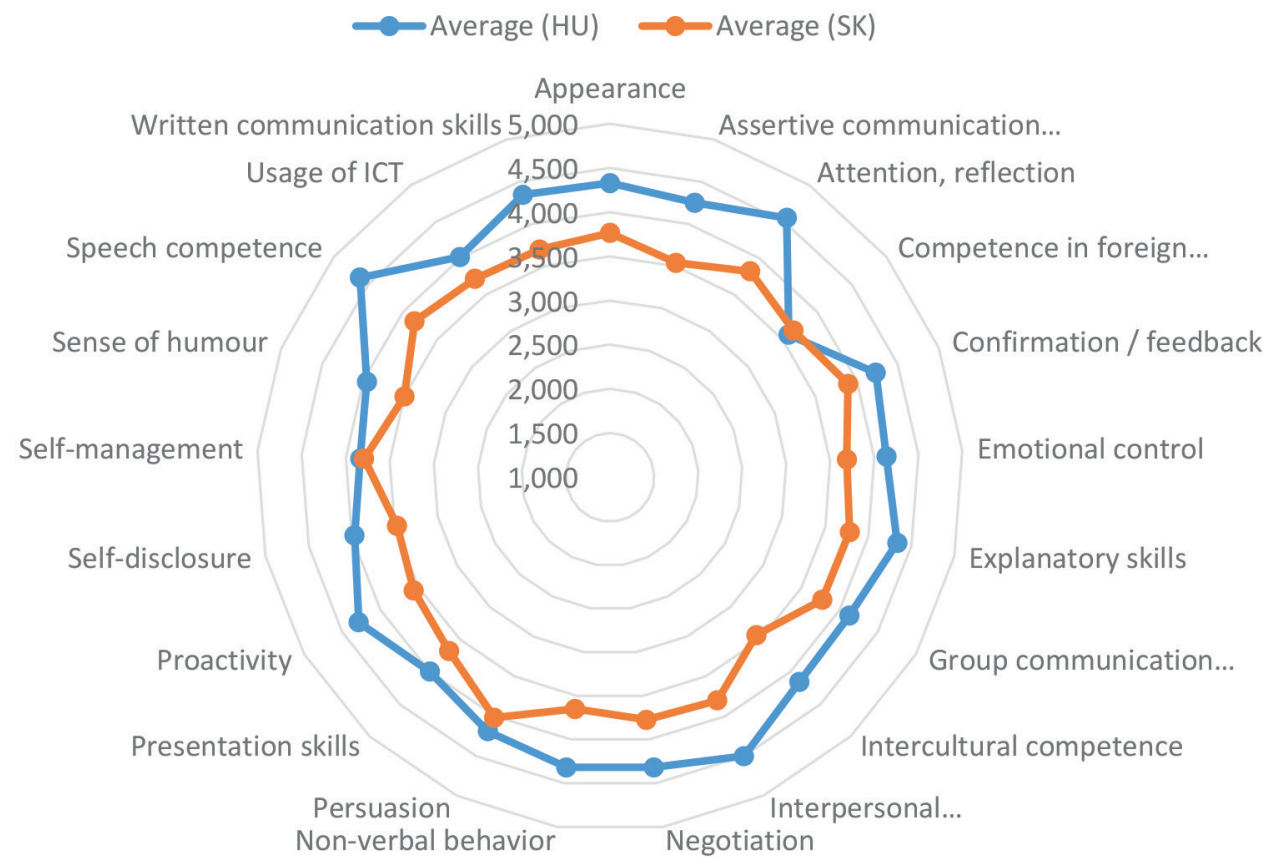

Fig. 3 Summary about the evaluation of the importance of different competences in Hungary and in Slovakia. Source: Own processing 
Observing the potential correlations between Hungarian and Slovakian judgements of each competence (Table 1), Pearson's chi-square tests show statistically significant correlations in 18 cases. Only three traits confirmed the null hypothesis, which means that, in these cases, there is no significant correlation between the two national groups' opinions. These traits are (1) self-management $(\chi 2(1)=0.59, p<0.05)$, (2) competences in foreign languages $(\chi 2(1)=0.35, p<0.05)$ and (3) persuasion skills $(\chi 2(1)=0.10, p<0.05)$. A fourth competence (ICT skills) is on the edge of verifying the null hypothesis $(\chi 2(1)=0.049, p<0.05)$; however, technically, the test shows a negative result, suggesting no correlations between the assessment of the importance of ICT skills.

No other statistically significant correlations can found, neither between the focus of the firms and the leaders' attitudes, nor between the age of the leaders and their opinions about the importance of communication competencies. Minor differences could be mapped; however, the small subsample did not allow researchers to define these as significant ones.

A fruitful approach to evaluate the experiences about and attitudes towards communication-centred trainings is to measure if the respondent has already had an individual experience with regards to training. Therefore, the questionnaire included a Yes/No question on the respondents' previous (existing) training experiences. Moreover, another open-ended question was built into the questionnaire about the respondents' training experiences, and what they have learnt from these training programmes. Altogether 30 respondents reported that they have already attended training programmes.

The evaluation of the results was carried out by reducing the responses to clearly identifiable competences mentioned in the short answer texts. In 14 cases, the mentioned competences could not be clearly identified, while the respondents reflected on their training experiences in general, highlighting their positive or negative opinions. In two cases, the respondents reported that they have already attended communication trainings; however, they did not give details or any reflections about them. These answers were categorised as "zero" content. Overall, 7 were categorically positive, while just as much negative feedback could be counted without there being any direct reference to communication competences. Among those answers where competences were referenced directly, group communication competence, assertiveness and leadership, received more than one mention among the respondents. Given that spontaneous mentions cannot thoroughly describe the respondents' opinions, these questions can only be regarded as "scratching the surface" and are even less applicable for measuring the efficiency of training programmes and vocational courses.

Table 1 Competence ranking in Hungary and in Slovakia. Source: Own processing

\begin{tabular}{|c|c|c|c|c|}
\hline Competence & Average (HU) & Rank (HU) & Average (SK) & Rank (SK) \\
\hline Appearance & 4,328 & 6. & 3,764 & 10. \\
\hline Assertive communication and confrontation & 4,250 & 10. & 3,538 & 18. \\
\hline Attention, reflection & 4,552 & 2. & 3,821 & 4. \\
\hline Competence in foreign languages & 3,586 & 21. & 3,660 & 15. \\
\hline Confirmation / feedback & 4,233 & 11. & 3,896 & 2. \\
\hline Emotional control & 4,138 & 14. & 3,689 & 13. \\
\hline Explanatory skills & 4,336 & 5. & 3,783 & 7. \\
\hline Group communication competence & 4,129 & 15. & 3,774 & 9. \\
\hline Intercultural competence & 4,155 & 13. & 3,434 & 21. \\
\hline Interpersonal communication & 4,500 & 3. & 3,802 & 5. \\
\hline Negotiation & 4,319 & 8. & 3,774 & 8. \\
\hline Non-verbal behavior & 4,319 & 7. & 3,651 & 16. \\
\hline Persuasion & 4,190 & 12. & 4,019 & 1. \\
\hline Presentation skills & 4,000 & 17. & 3,679 & 14. \\
\hline Proactivity & 4,284 & 9. & 3,566 & 17. \\
\hline Self-disclosure & 3,966 & 18. & 3,472 & 20. \\
\hline Self-management & 3,836 & 20. & 3,792 & 6. \\
\hline Sense of humour & 3,957 & 19. & 3,500 & 19. \\
\hline Speech competence & 4,621 & 1. & 3,830 & 3. \\
\hline Usage of ICT & 4,017 & 16. & 3,717 & 11. \\
\hline Written communication skills & 4,345 & 4. & 3,698 & 12. \\
\hline
\end{tabular}


Furthermore, data analysis showed that there is no significant correlation between the businessmen's leadership experience and their attitudes towards communication competence trainings $(r=0.2)$. The overall average satisfaction with communication trainings among those businessmen who have ever attended communication trainings is 2.53 on a $0-3$ scale. This result can be interpreted as follows: those businessmen who have already attended training courses concerning communication skills evaluated their experiences averagely between "partially useful" and "quite useful". The answers may be distorted by the previous questions (importance of different skills) that elicited opinions about the usefulness of developing these competences. Moreover, the focus of this questionnaire had already been put on measuring the assessment of the importance of various skills, instead of judging the role and importance of on-the-job training and other vocational courses. Therefore, the explicitly positive and negative feedback can only be evaluated as anecdotal supplementary evidence.

\section{Conclusions}

Hungarian company leaders and decision makers named speech competencies, attention/reflection, and interpersonal communication skills as the most crucial ones in communication. In Slovakia, persuasion, communicative feedback and speech competencies proved to be the most important communication traits. Scanning through the low-end of the importance list, Hungarian respondents think that a sense of humour, self-management and foreign language skills may be the least relevant competences among their employees. At the same time, Slovakian leaders regard a sense of humour, self-disclosure and intercultural competencies to be the less important competences for an individual to possess at their workplaces.

We can inevitably state that the biggest differences between Hungarian and Slovakian assessments (speech competence 0.79 ; attention/reflection 0.73 ; intercultural competence 0.72 ; proactivity 0.72 ; assertive communication and confrontation 0.71 ) are outside the statistical margin of error, showing a significant discrepancy between the two different nationalities.

The total importance score, just like the overall average of importance assessment of each competence category is lower on the Slovakian side. (The dispersion of Hungarian category averages is 0.238 , their variance is 0.057 , in comparison with the Slovakian dispersion of 0.142 , var $=0.02$.) This can be interpreted so that the respondents judge generally more strictly in terms of the importance of competencies, or they regard the indicated competencies not as important as their Hungarian colleagues, or they might can name other (more important) competencies unfortunately, the latter question was not included into the survey. Interestingly, only the competence in foreign languages proved to be more important in Slovakian companies (ave $=3.66$ ) than in Hungarian ones (ave $=3.59$ ).

The reason of this general difference in judgement can also be explained by the differences in the observed companies' working profiles. However, both on the Hungarian and on the Slovakian side, we managed to create a miscellaneous sample in terms of assignment, from information and communication sector through financial and insurance companies to the building industry and manufacturing.

One limitation of this study is the unsatisfactory selection of the companies' field(s) of activity. A more thorough and more differentiated sampling of assignments could result in finer shades of differences between competence assessments.

The second concern is the small sample size. During the research period, it proved to be the case that company leaders are difficult to reach for a survey longer than five minutes, a stark fact which in practice hindered the numeric extension of the sample. Furthermore, in accordance with the public administration categories of the Hungarian enterprises - the researchers decided to put individual proprietorships into the same sample pool as the bigger companies, further designated as members of subcategories (one-man entrepreneurships, micro-enterprises, small enterprises, medium enterprises). Another study, dealing with only one of the above-mentioned categories and involving a larger number of such enterprises could yet yield clearer measurements and more reliable results.

In terms of communication training experiences, the leaders reported that group communication competencies, assertiveness and leadership competencies were the main areas of focus. The strong presence of group communication skills training among professional training programmes is easy to interpret: whether these sessions involve a smaller or bigger amount of employees, it is practical to concentrate on how they work together - logically, mainly in medium-sized enterprises, and sometimes in small ones, too. Leadership skills training appears mainly in specific training courses or workshops when a group of leaders are present. However, in this regard we can also imagine coaching and counselling situations, which have these skills at their core. Assertiveness, however, is a universal behavioural pattern which should be developed among leaders and also among their subordinates. 
Clearly, the satisfactory with communication training programmes neither depends on the participant's amount of leadership experience nor on the companies' field(s) of activity nor on the nationality (venue) of the companies. The overall satisfactory rate is 2.53 in a four-grade scale among those who ever attended in communication trainings (their proportion was $51.8 \%$ in the whole sample).

The study did not investigate what proportion of companies integrate communication training programmes with their on-the-job learning and have taken steps to develop such activities countrywide; therefore, we cannot compare our results to other existing data. The main reason for this is the unsatisfactory operationalisation of the concept and content of "communication training programmes": a group-building weekend outdoor activity can be included under the heading of this topic just as much as a specific small-group coaching with a strong focus. Besides identifying this limitation, we can state that a hands-on, practical categorisation of the professional communication training scene would be desirable.

\section{References}

Akhmedjanov, A. R. (2020) "Competency-based Human Resources Management System at Service Enterprises", Journal of Advanced Research in Dynamical and Control Systems, 12(SP7), pp. 144-149.

https://doi.org/10.5373/jardcs/v12sp7/20202092

American Management Association (2010) "AMA 2010 Critical Skills Survey: Executives Say the 21st Century Requires More Skilled Workers", [online] Available at: http://www.p21.org/documents/ CriticalSkillsSurveyExecutiveSummary.pdf [Accessed: 25 December 2019]

Athey, T. R., Orth, M. S. (1999) "Emerging competency methods for the future", Human Resource Management. 38(3), pp. 215-225. https://doi.org/10.1002/(SICI)1099-050X(199923)38:3<215::AIDHRM4>3.0.CO;2-W

Briscoe, J. P., Hall, D. T. (1999) "An alternative approach and new guidelines for practice", Organizational Dynamics, 28(2), pp. 37-52. https://doi.org/10.1016/s0090-2616(00)80015-7

Chan, A. C. K., Du-Babcock, B. (2018) "Leadership in action: an analysis of leadership behaviour in intercultural business meetings", Language and Intercultural Communication, 19(2), pp. 201-216. https://doi.org/10.1080/14708477.2018.1508291

Chiniara, M., Bentein, K. (2018) "The servant leadership advantage: When perceiving low differentiation in leader-member relationship quality influences team cohesion, team task performance and service OCB", The Leadership Quarterly, 29(2), pp. 333-345. https://doi.org/10.1016/j.leaqua.2017.05.002

Cohrs, C., Bormann, K. C., Diebig, M., Millhoff, C., Pachocki, K., Rowold, J. (2019) "Transformational leadership and communication", Leadership \& Organization Development Journal, 41(1), pp. 101-117.

https://doi.org/10.1108/lodj-02-2019-0097
As a final statement, we emphasise a pleasing result: a surprisingly large amount of the leaders and sub-leaders of the observed micro-, small and medium enterprises have already attended communication training programmes. (A possible limitation may, however, be that those leaders who have some interest in communication skills can be more easily persuaded to fill in a questionnaire about communication than ones who cannot be triggered by the topic.) Their overall satisfactory perception $(63.25 \%)$ shows that most of them think these opportunities were useful for the development of their working skills. Alongside with this, further studies could be carried out to observe if they think the same way in terms of their subordinates' development, or, in other words, if they think that spending money on the employees' communication training is a recoverable cost.

\section{Acknowledgement}

The paper was supported by the Széchenyi 2020 Human Resource Development Operational Programme (EFOP-3.6.1-16-2016-00013).

Gallo, C. (2018) "Leadership communication for the $21^{\text {st }}$ century knowledge economy", Leader to Leader, 2018(90), pp. 18-23. https://doi.org/10.1002/1t1.20385

Gil, A. J., Rodrigo-Moya, B., Morcillo-Bellido, J. (2018) "The effect of leadership in the development of innovation capacity", Leadership \& Organization Development Journal, 39(6), pp. 694-711. https://doi.org/10.1108/lodj-12-2017-0399

Goleman, D. (1998) "The emotional intelligence of leaders", Leader to Leader, 1998(10), pp. 20-26. http://doi.org/10.1002/1t1.40619981008

Hackman, M. Z., Johnson, C. E. (2004) "Leadership: A Communication Perspective", Waveland Press, Long Grove, IL, USA.

Hollenbeck, G. P., McCall, M. W., Silzer, R. F. (2006) "Leadership competency models", The Leadership Quarterly, 17(4), pp. 398-413. https://doi.org/10.1016/j.leaqua.2006.04.003

Ichimiya, G. (2019) "Leader Development Through Communication with Subordinates", Organizational Dynamics, 48(2), pp. 44-52. https://doi.org/10.1016/j.orgdyn.2018.12.001

Karácsony, P., Machová, R. (2014) "Comparison of the Employee Motivational Tools in Industrial Companies", In: $5^{\text {th }}$ Central European Conference in Regional Science, Košice, Slovak Republic, pp. 346-350.

Lapierre, L. M., McKay, L. (2002) "Chapter 16 - Managing Human Capital with Competency-Based Human Resources Management", In: Bontis, N. (ed.) World Congress on Intellectual Capital Readings, Butterworth-Heinemann, Woburn, MA, USA, pp. 306-319. https://doi.org/10.1016/b978-0-7506-7475-1.50020-8

Lišková, S., Tomšík, P. (2013) "Competency-based approach to human resources management", Agricultural Economics, 59(11), pp. 496-504.

https://doi.org/10.17221/68/2013-agricecon 
Machida-Kosuga, M. (2017) "The Interaction of Efficacy and Leadership Competency Development", New Directions for Student Leadership, 2017(156), pp. 19-30. https://doi.org/10.1002/yd.20268

Meiners, E. B. (2019) "Unpacking the metaphors of leadership using the Leadership Communication Grid: Knowledge, skills, and abilities", Communication Teacher, 33(4), pp. 266-270. https://doi.org/10.1080/17404622.2019.1575427

Mintzberg, H. (1994) "Rounding out the manager's job", Sloan Management Review, 36(1), pp. 11-26. https://doi.org/10.1016/0024-6301(95)92171-0

Ryan, R. (2008) "Chapter 9 - Skills of the leadership development specialist", In: Ryan, R. (ed.) Leadership Development: A Guide for HR and Training Professionals, Butterworth-Heinemann, Oxford, UK, pp. 183-198. https://doi.org/10.1016/b978-0-7506-8193-3.50012-6

Smith, L., Mounter, P. (2005) "Effective Internal Communication", Kogan Page Limited, London, UK.

Spencer, L. M., Spencer, S. M., (1993) "Competence at work: Models for superior performance", John Wiley \& Sons, New York, NY, USA.
Vinichenko, M. V., Karácsony, P., Li, N. P., Kirillov, A. V., Melnichuk, A. V. (2018) "Improving efficiency of personnel training and development of the personnel reserve in organizations", Opcion, 34(85), pp. 1049-1064.

Warin, B., Kolski, C., Sagar, M. (2011) "Framework for the evolution of acquiring knowledge modules to integrate the acquisition of highlevel cognitive skills and professional competencies: Principles and case studies", Computers \& Education, 57(2), pp. 1595-1614. https://doi.org/10.1016/j.compedu.2011.02.013

Williams, R. (2019) "Honing your communications skills to win allies, inside and outside your organization", Leader to Leader, 2019(94), pp. 7-11. https://doi.org/10.1002/1t1.20459

Yıldırım, F., Trout, I. Y., Hartzell, S. (2019) "How Are Entrepreneurial Intentions Affected by Emotional Intelligence and Creativity?", Periodica Polytechnica Social and Management Sciences, 27(1), pp. 59-65.

https://doi.org/10.3311/PPso.12619 